\title{
Laudinhos antropológicos: as crianças indígenas e os processos de demarcação de terra
}

\section{Little anthropological reports: indigenous children and land demarcation processes}

Emilene Leite Sousa ${ }^{1}$

\begin{abstract}
Resumo: Este artigo defende a importância da participação das crianças indígenas nos processos de demarcação de terra a partir de uma reflexão sobre a produção de conhecimento pelas crianças indígenas Tentehar-Guajajara. Por meio de uma análise dos processos de produção dos saberes construídos pelas crianças através da sua interação com o ambiente físico e a cultura a que pertencem, pretendo argumentar em favor do reconhecimento das crianças como importantes sujeitos nos processos de demarcação de terra, pelo fato de estas não estarem ausentes desses processos, serem claramente afetadas por eles, serem sujeitos interessados e possuírem vínculos com a terra e representações diversas desta. Ademais, as pesquisas desenvolvidas entre crianças indígenas demonstram que elas têm opiniões próprias sobre o processo, uma relação particular com a terra, estão atentas às demandas da comunidade e produzem conhecimento entre si e junto aos adultos, além de compartilhar os demais sinais diacríticos da cultura na qual estão inseridas. Além do mais, serão elas as herdeiras de todo o legado. Por essa razão, as crianças se constituem como importantes sujeitos para os laudos antropológicos. Este artigo parte de um diálogo com as discussões atuais sobre teorias do conhecimento (BARTH, 1995; 2000; CARNEIRO DA CUNHA, 2009; COHEN, 2010; INGOLD, 2000; LASMAR, 2009) considerando os contextos diversos na produção do conhecimento (TASSINARI, 2001; COHN, 2002) e as pesquisas realizadas por mim entre as crianças indígenas Tentehar-Guajajara do Maranhão, Brasil.
\end{abstract}

Palavras-chave: crianças indígenas; produção de conhecimento; laudos antropológicos.

\begin{abstract}
This article defends the importance of indigenous children participation in land demarcation processes, reflecting on the production of knowledge by the Tenetehara-Guajajara indigenous children. By means of an analysis of the knowledge production processes built by children in their interaction with the culture and physical environment to which they belong, I intend to argue in favor of the recognition of children as important subjects in land demarcation processes, because they are not absent from these processes,
\end{abstract}

${ }^{1}$ Universidade Federal do Maranhão (UFMA), Imperatriz, Maranhão, Brasil.

Tellus, Campo Grande, MS, ano 18, n. 35, p. 113-138, jan./abr. 2018 
and are clearly affected by them, as interested subjects who are tied to the land and its diverse representations. In addition, the research conducted among indigenous children shows they have their own opinions about the process and a specific relationship with the land. It also shows they are attentive to community's demands and produce knowledge among themselves and with adults, as well as share other diacritical signs of their culture. Furthermore, they will be the heirs of the entire legacy. Therefore, children are important subjects for Anthropological reports. This article is part of a dialogue with the current debate about the theories of knowledge (BARTH, 1995; 2000; CARNEIRO DA CUNHA, 2009; COHEN, 2010; INGOLD, 2000; 2002; 2004; 2010; LASMAR, 2009), considering the diverse contexts of knowledge production (TASSINARI, 2001; COHN, 2002) and the researches I have carried out among the TeneteharaGuajajara indigenous children of Maranhão, Brazil.

Keywords: indigenous children; knowledge production; anthropological reports.

\section{APRESENTAÇÃO}

Lá... lá havia apenas crianças, e o tempo todo eu estava lá com as crianças, apenas com as crianças. Eram crianças daquela aldeia, toda a tropa que estudava na escola. [...] Pode-se dizer tudo a uma criança tudo; sempre me deixou perplexo a idéia de como os grandes conhecem mal as crianças [...] Não se deve esconder nada das crianças sob o pretexto de que são pequenas e ainda é cedo para tomarem conhecimento. Que idéia triste e infeliz! [...] Os grandes não sabem que até nos assuntos mais difíceis a criança pode dar uma sugestão sumamente importante. (Príncipe Míchkin em O ldiota de Dostoiévski).

A partir da pesquisa realizada entre as crianças Tentehar-Guajajara do Maranhão, este artigo visa refletir sobre teorias nativas de conhecimento e seus processos próprios de produção na infância, para argumentar em favor das crianças indígenas como importantes sujeitos a serem considerados nos processos de demarcação de terra. Para tanto, utilizo-me das discussões atuais sobre teorias do conhecimento, os saberes nativos e a aprendizagem na infância para lançar luz sobre o caso das crianças indígenas Tentehar-Guajajara do Maranhão, e a importância destas nos processos de demarcação de terra, considerando os processos de produção dos saberes na infância, a interação das crianças com o ambiente físico 
e a cultura a que pertencem. Acredito que as crianças são sujeitos em potencial nessas circunstâncias pelo fato de estas não estarem ausentes desses processos, serem claramente afetadas por eles, serem atores interessados e possuírem vínculos com a terra e representações diversas desta como ocorre com os adultos, além disso, serão elas as herdeiras do legado adquirido através desses processos.

Ademais, as pesquisas desenvolvidas entre crianças indígenas demonstram que as crianças têm opiniões próprias sobre o processo e sua relação com a terra, estão atentas às demandas da comunidade, e compartilham os conhecimentos nativos além dos demais sinais diacríticos da cultura na qual estão inseridas.

Neste artigo, não considerarei a aprendizagem escolar, embora acredite que, para analisar o processo de construção dos saberes nativos entre crianças indígenas, faz-se necessário levar em consideração todas as formas de conhecer e aprender que as culturas indígenas julgarem importantes - inclusive essa. No entanto aqui pretendo enfatizar o processo de construção do conhecimento não escolar, mas aquele que acontece "lá fora", pelos espaços da aldeia e pelo contato constante das crianças com o ambiente que Ihes cerca.

Cabe também ressaltar que não concebo o conhecimento como um todo harmonioso, coeso que se possa apreender como representando o conhecimento geral de um povo, afinal, há diferentes corpus de conhecimento e diferentes formas de saber dentro das culturas e entre elas. Essa heterogeneidade fica ainda mais evidente se comparada através do recorte crianças/adultos.

Não argumento, portanto, que as crianças devam ser percebidas como sujeitos nesses processos porque elas sabem as mesmas coisas que os adultos. Pelo contrário. As crianças devem e precisam ser consideradas porque estas possuem conhecimentos e saberes distintos dos que detêm os adultos. Elas não sabem menos, elas sabem outra coisa (COHN, 2005).

Assim é que este artigo se insere nas discussões antropológicas sobre a criança, o seu reconhecimento como importante sujeito de pesquisa e visa ampliar esse reconhecimento para além da esfera acadêmica e abrangência antropológica, no intuito de que os agentes envolvidos nos processos de demarcação de terras indígenas considerem as crianças como importantes sujeitos, sujeitos ativos nesse processo e afetados por ele, dando-Ihes o direito de serem consideradas ao longo do processo. 


\section{PAPEL SOCIAL DA CRIANÇA INDÍGENA}

Nas últimas décadas, os antropólogos no Brasil têm conjugado esforços para registrar as infâncias indígenas, respeitando sua heterogeneidade, pois encontramos entre os indígenas variadas formas de tratar esse período da vida.

Tassinari (2007) dedicou-se à análise de cinco concepções indígenas sobre a infância que são recorrentes nestes estudos: 1) o reconhecimento da autonomia da criança de sua capacidade de decisão; 2) o reconhecimento de suas diferentes habilidades frente aos adultos; 3 ) a educação como produção de corpos saudáveis; 4) o papel da criança como mediadora de diversas entidades cósmicas; 5) o papel da criança como mediadora dos diversos grupos sociais.

Segundo a autora, as sociedades indígenas reconhecem autonomia e legitimidade às falas infantis, em contrapartida ao modo ocidental de conceber a criança. Isso justificaria a importância de pesquisar o que as crianças indígenas têm a dizer e as maneiras como as várias sociedades indígenas concebem a infância (TASSINARI, 2007).

Fundamentando sua análise, Tassinari (2007) mapeia as pesquisas realizadas sobre crianças indígenas no Brasil, demonstrando que aspectos como a autonomia e a independência das crianças indígenas e a ausência de castigos já apontavam para um modo diferente de se conceber a infância nessas culturas.

Pensando essa diferenciação dos modos de se perceber a infância, Mello (2006) afirma que, entre os Guarani, a criança é vista como um ser completo, portador de um espírito que precisa ser cativado para permanecer na terra. Assim, as atitudes das crianças são respeitadas e sua autonomia pela busca de conhecimentos é reconhecida.

Cohn (2000) discute a autonomia infantil entre os Kayapó, para quem as crianças "tudo sabem por que tudo veem", a despeito de sua possibilidade de estar em todos os lugares - alguns até inviáveis para os adultos. Ao mesmo tempo, os Kayapó acreditam que as crianças "nada sabem porque são crianças", referindo-se ao fato de ainda não terem seus órgãos desenvolvidos para compreender tudo.

Essa liberdade de escolha das crianças indígenas deve ser compreendida como relativa, sempre em relação à vivência adulta (TASSINARI, 2009 ). Especialmente porque toda liberdade resulta em poder e responsabilidade. 
As crianças indígenas são as responsáveis pela sua socialização participando ativamente da vida social, como demonstra Codonho (2009) para quem parte da socialização das crianças Galibi-Marworno do Amapá ocorre no interior de grupos de crianças onde ocorre a "transmissão horizontal de saberes", ou seja, as crianças não só escolhem o que desejam saber, mas também transmitem esses saberes entre si. De certa forma, o cuidar uns dos outros entre as crianças não deixa de ser um modo de transmissão de saberes. Elas, fazendo, ensinam/ aprendem/cuidam/brincam.

Darcy Ribeiro (1996), ao pesquisar os Urubu-Kaapor, tratando do cotidiano, hábitos e costumes do povo, revela a atuação autônoma e o papel que a criança Urubu-Kaapor ocupa em sua cultura ao relatar o dia da "guria mais trabalhadora da aldeia" demonstrando como, entre elas, as crianças cuidam/ensinam/aprendem.

O reconhecimento da autonomia das crianças e da interdependência entre elas não isenta os adultos da responsabilidade por educá-las e fornecer-lhes condições de aprendizagem, especialmente nas culturas onde mostrar "como se faz algo" pode ter maior valor do que "falar a respeito de". É o que fazem os Karipuna ao orientarem os pequenos trabalhos das crianças, o único que pode ser abandonado inconcluso sem gerar problemas (TASSINARI, 2007).

Também recorrente é a associação das crianças pequenas aos deuses e animais, especialmente entre os Guarani, para quem crianças, deuses e animais, todos têm pontos de vista (TASSINARI, 2007; VIVEIROS DE CASTRO, 2006. As crianças tanto podem ser mediadoras entre várias categorias cosmológicas- como demonstra Tassinari (2007)- como entre vivos e mortos, conforme revela Alvares (2004).

O papel da criança indígena tanto pode assumir a mediação entre diversos grupos sociais, inimigos ou estrangeiros; como índios e não índios, como até mesmo entre parentes por afinidade no interior de uma mesma sociedade (TASSINARI, 2007).

A corporalidade tem sido um dos elementos a merecer destaque nas pesquisas sobre crianças indígenas, especialmente no que diz respeito à educação da criança que ocorre no interior das culturas indígenas através da in(corpo)ração da aprendizagem, que utiliza como um dos seus principais instrumentos o corpo da criança (LOPES DA SILVA; NUNES; MACEDO, 2002; TASSINARI, 2007). 
A educação também compõe o rol dos temas a que se dedicam estudiosos da infância indígena. Especialmente quando o modelo de educação escolar se torna mais forte nas aldeias, importados das sociedades não indígenas e aplicado às culturas indígenas sob a premissa quase universal de que "lugar de criança é na escola" (SOUSA, 2007; TASSINARI, 2009 ).

Por fim, Tassinari (2007) aponta o caminho para as pesquisas com crianças indígenas: a) reconhecimento de que ainda temos poucos dados etnográficos; b) necessidade de deixar de lado nossa visão de infância e os estereótipos sobre a candura ou crueldade indígenas; c) reconhecimento da diversidade sociocultural indígena e do caráter provisório das generalizações.

Esse reconhecimento da infância indígena como possível campo de conhecimento e das crianças como sujeitos legítimos de pesquisa me ajudam a argumentar em favor da importância das crianças serem percebidas nos processos de demarcação de terra.

\section{CONHECIMENTOS NATIVOS SOB A LUPA ANTROPOLÓGICA}

Em defesa das crianças indígenas como sujeitos a serem considerados nos processos de demarcação de terra, este artigo se dedica à compreensão dos processos de construção de saberes nas sociedades indígenas, especialmente no que diz respeito às crianças, com o intuito de apreender o lugar que estas ocupam na cultura indígena e lançar luz sobre a inserção delas no seio da comunidade e sua relação com a terra.

Conforme Lasmar (2009), as teorias nativas do conhecimento devem ser analisadas através de vários artefatos metodológicos em razão da compreensão de que o conhecimento extrapola as formas orais em sua construção e transmissão, podendo inclusive obter maior ênfase nos modos não orais a depender da cultura que se observa e da fase do ciclo de vida em análise.

Mauss (1996) é um dos autores que trata do reconhecimento de formas não orais de transmissão de saberes. Segundo esse autor, o entendimento que, no geral, se atribui às "tradições" é embasado, de modo inconsciente, em formas de transmissões de saberes orais e escritas. Porém há muitos outros aspectos da tradição que não se restringem a essas formas de ensino e aprendizagem, sendo transmitidas de outras maneiras que também se cristalizam, é o caso das técnicas corporais. 
Como Mauss, Cohen (2010) reafirma a importância central da experiência corpórea no conhecimento humano. Conforme a autora, análises etnográficas convincentes demonstram a centralidade dos estados corporais na construção do conhecimento. Ora, mas como fatores corporais influenciam a tomada de tais conhecimentos?

Segundo Cohen, a recuperação do conhecimento parcial implica a encenação de situações que levou a sua codificação. A recuperação das informações mais básicas referentes a objetos do cotidiano implica simulação da situação de estar lá. Cohen destaca: "se quisermos não só descrever e interpretar, mas explicar como o corpo está implicado nas aquisições de conhecimento, os conceitos problematizados devem ser complementados com os conceitos operacionalizados" (COHEN, 2010, p. 196).

A partir disso, é que Cohen passa a tratar o conhecimento incorporado na transmissão cultural. Mas quais seriam os mecanismos que estabeleceriam o canal de tal conhecimento? Quais são as dimensões materiais do processo de aprendizagem? Como estes permitem restringir a transmissão da cultura?

Tentando responder a essas questões, Cohen alega que a transmissão cultural é fortemente influenciada pelo contexto físico em que ocorre, o que ela nomeará cognição aterrada. Segundo a autora, o que sabemos depende do cérebro, corpo e ambiente em que a transmissão ocorre, sendo esses três elementos que comporiam a trilogia do conhecimento. Cada vez mais processos cognitivos como percepção, concepção, atenção, memória e motivação apresentam-se como baseados em seus contextos físicos.

Segundo Cohen (2010), a explicação sobre o surgimento, disseminação, armazenamento e transformação do conhecimento enfrenta numerosos obstáculos teóricos e metodológicos. Esses obstáculos podem ser superados se considerarmos a interdisciplinaridade. Todavia os antropólogos- na prática do being there- estão em posição privilegiada em relação a outros profissionais para gerar relatos precisos descritivos e teóricos do fazer de diversos tipos de conhecimento.

Para desvendar não apenas o "como sabemos", mas também o "como chegamos a conhecer" devemos vislumbrar os mecanismos sociais e cognitivos e processos pelos quais diferentes formas de conhecimento são gerados envolvendo condições de ativação diferentes e produzindo diferentes resultados. 
Também se destacam como importante referência os estudos sobre teorias nativas do conhecimento de Barth $(1975 ; 1987 ; 1995 ; 2000)$. Esse autor ressalta o caráter construtivo/produtivo das culturas, enfatizando processos de criatividade e mudança na transmissão de "tradições de conhecimento". O autor demonstra através de sua etnografia como, entre grupos da Nova Guiné, alguns indivíduos, os experts rituais, são designados culturalmente para manter sob seu cuidado certos conhecimentos que só podem ser revelados em rituais misteriosos que ocorrem em intervalos de vários anos, entre os quais os ritos de iniciação são os menos frequentes, porém mais importantes. O autor procura mostrar que formas e conteúdos da tradição da cosmologia dos nativos das montanhas podem ser remodeladas pelo especialista durante sua performance ritual, destacando a importância da conversação entre este e sua audiência.

Barth (1995) critica a ideia de cultura como um todo integrado e partilhado localmente e propõe a consideração do "conhecimento como uma importante modalidade da cultura", entendendo-o como uma ferramenta que "as pessoas empregam para interpretar e agir sobre o mundo: sentimentos bem como pensamentos, condutas incorporadas bem como taxonomias e outros modelos verbais." Considerando que há diferentes corpos de conhecimentos e diversos modos de conhecimento intra e entre as culturas, o autor afirma que, a partir desse tipo de abordagem, outros tipos de questionamentos são considerados em relação à cultura, tais como: "variação, posicionamento, prática, troca, reprodução, mudança e criatividade" (BARTH, 1995, p. 66-7). Enfim Barth propõe que se pense cuidadosamente sobre como diferentes tipos de conhecimentos são constituídos, produzidos e utilizados.

Barth (1995) defende uma perspectiva que considera o conhecimento como uma das principais modalidades de cultura e a cultura como conhecimento, já que as pessoas se comprometem com o mundo através da ação. A antropologia se dedica desde sempre a decodificar representações e ações, o que Barth defende é que o que está por trás dessas ações e representações são processos de conhecimento. Para Barth, o conhecimento oferece a matéria-prima para a reflexão e ação dos indivíduos. A cultura trata de abarcar as reflexões e ações. Mas o conhecimento se antecipa a ação. Conforme Barth, atentando para isso poderemos nos envolver em campo com as ideias de um povo, não como mero exemplo de cultura, mas com a sua aprendizagem para a vida².

\footnotetext{
2 Para Barth falta humildade aos antropólogos. Em referência a Malinowski, ele argumenta que
} 
Segundo Barth, o reconhecimento da cultura como conhecimento é uma maior consciência da gama de conhecimentos desses povos que não são abrangidos pela antropologia ${ }^{3}$. Isso nos levará também a aprender e nos engajar nos contextos de conhecimento e prática que moldam a nossa interação com as pessoas.

Para captar esses processos diversos de conhecimento, nossa análise deve atentar para a inspeção dos critérios diferentes de validação em diferentes tradições de conhecimento que são produzidos por meio desses diferentes critérios. Podemos assim, comparar os critérios de validação do conhecimento antropológico e outros conhecimentos e assim entender os tipos de conhecimento que eles geram e os atos e moralidades que sustentam.

Aqui se destaca também o conhecimento como inferência: "ele sabe o que viu, ouviu, leu, o que foi dito e o que, a partir de tudo isso, ele inferiu" (RUSSEL, 1948 apud BARTH, 1995). Assim é que o indivíduo pode ter uma série de crenças em lugares onde nunca esteve e acontecimentos que não presenciou, mas que foram experimentados por outras pessoas que lhe descreveram, e ele aceitará como válido. É o escopo do nosso conhecimento confiando nos critérios de validação dos outros. Nesse sentido, é que conhecimento é relacionamento e se fundamenta pelo processo de socialização.

Através do desmembramento do conhecimento em a) conhecimento substancial; b) meios de comunicação; c) organização social é que Barth pretende chegar ao nível da ação humana particular e dos eventos, já que sua ênfase está no indivíduo e na ação. Devemos atentar para os atos dos conhecedores, o povo que detém, aprende, produz e aplica o conhecimento em suas várias atividades e vidas.

Essas reflexões tornam-se extremamente úteis não somente para pensarmos acerca dos modos de produção e transmissão de conhecimentos nativos, mas também das perspectivas através das quais a antropologia vem apreendendo e se apropriando desses conhecimentos. Nesse sentido, cabe refletir sobre como os saberes nativos podem ser compreendidos em relação aos conhecimentos científicos.

os antropólogos esperam que os conceitos nativos iluminem a nossa própria compreensão, fornecendo a carne para o nosso esqueleto.

${ }^{3}$ Mas, o que a nossa ideia de conhecimento evoca como cultura? Nesse sentido, a cultura, conceito, também é uma construção do conhecimento. 
Ingold (2000), a partir de sua proposta de uma ecologia da vida, traz à baila a discussão sobre as distintas formas de produção de saberes. Aproxima o modo como seu pai lhe ensinava seus conhecimentos botânicos ao modo como os Walbiri da Austrália Central compartilham seus conhecimentos com seus iniciados. Essa forma de ensino, de geração a geração, toma como base a ideia de que existem verdades imanentes à paisagem, as quais devem ser reveladas para os noviços através da observação e experiência direta. O conhecimento é compartilhado pelos mais velhos que contam histórias em contexto e mostram a paisagem e assim fornecem chaves para o significado. Assim o noviço vai do conhecimento mais externo até o mais interno, profundo, através de revelações. As verdades inerentes ao mundo são desveladas para que sejam apreendidas diretamente. Trata-se de uma educação sensorial, em que processos de aprendizagem podem ser concebidos como a aquisição progressiva de chaves para se perceber o mundo ao redor.

Para Ingold (2000), organismo e ambiente "não deve denotar um composto de duas coisas, mas uma totalidade indivisível", essa totalidade não é uma entidade limitada, mas um processo em tempo real. Meu ambiente é o mundo como ele existe e adquire sentido em relação a mim. Além disso, o ambiente nunca é completo, por ser produto das atividades dos seres vivos que estão continuamente em construção.

Com base nisso, para Ingold (2000), o conhecimento do mundo é apreendido através do envolvimento do organismo com o ambiente ${ }^{4}$, e não pela transmissão de informação, pois "a informação, em si, não é conhecimento, nem nós adquirimos mais conhecimento através da sua acumulação. Nossa cognoscibilidade consiste, antes, na capacidade de situar essas informações e entender seu significado, no contexto de um envolvimento direto com a percepção de nossos ambientes" (INGOLD, 2000). E nós desenvolvemos essa capacidade, conforme o autor, por nos terem mostrado as coisas sobre as quais aprendemos.

Nesse sentido, a transferência de crenças e conhecimentos de geração para geração poderia ser vista como uma maneira de inscrição do conhecimento cultural nos objetos ou caracteres. "Em outras palavras [...] formas culturais podem ser codificadas na paisagem assim como representações conceituais são codificadas no meio sonoro" (INGOLD, 2000, p. 21).

\footnotetext{
${ }^{4}$ Também para Geertz (1997) formas de conhecimento são sempre inevitavelmente locais, indivisíveis de seus instrumentos e invólucros.
} 
A ecologia da vida, proposta pelo autor, se aproxima da ecologia sensciente, que David Anderson (apud Ingold, 2000) descreve para os caçadores da região Taymir do norte da Sibéria no que diz respeito às suas relações com animais e outros seres do ambiente. Nesse sistema, não há a produção de conhecimentos formais fora do contexto de aplicação prática, mas sim a construção de conhecimentos baseada em sentimento, os quais consistem em capacidades, sensibilidades e orientações desenvolvidos através da condução da vida num ambiente particular. Este tipo de conhecimento pode também ser chamado intuição.

Para Ingold, é pela capacidade de raciocinar que a humanidade (discurso ocidental) se distingue da natureza; e é por meio dessa capacidade que a ciência moderna distingue o conhecimento das práticas das pessoas em "outras culturas". Desse modo, a razão abstrata é um produto da composição de duas dicotomias: entre a humanidade e a natureza, e entre a modernidade e a tradição (INGOLD, 2000). A distinção natureza/cultura remete à dicotomização de que a explicação científica é atribuída à observação e análise racional, e as representações indígenas são atribuídas à acomodação da experiência subjetiva dentro de "convicções" de uma racionalidade questionável.

Invertamos a relação indo da experiência do mundo à razão abstrata. Pois, como nos diz Ingold, "devemos descer das alturas do imaginário da razão abstrata e recolocar-nos uma participação ativa e permanente com nosso ambiente, se quisermos chegar a uma ecologia que é capaz de recuperar a realidade do próprio processo da vida" (INGOLD, 2000). Seu objetivo é substituir a dicotomia natureza e cultura (ambiente/organismo) a fim de recuperar uma ecologia da vida real.

É nesse sentido que Ingold aborda a noção de intuição. É por isso que a perspectiva soberana da razão abstrata, sobre a qual a ciência Ocidental coloca a sua reivindicação de autoridade, é praticamente inatingível: uma inteligência que foi completamente independente das condições de vida no mundo não pode entender os seus próprios pensamentos. Desse modo, concluímos que apenas através da razão nós não damos conta do mundo, devendo usufruir da intuição, esse atributo da natureza 5 .

\footnotetext{
${ }^{5}$ Para Ingold (2000), a compreensão do mundo não pode existir sem o vivido, de modo que o contato, interação com o ambiente, é a garantia para a compreensão dos modos de ser no mundo. Ele nos convida a voltar do racionalismo/intelectualismo extremo para a empiria, sendo orientados pela nossa própria intuição.
} 
Por fim, o autor analisa como a "intuição" também é vista como uma forma de conhecimento inferior. O entendimento intuitivo não é contrário à ciência ou à ética; nem apela para o instinto mais do que a razão, ou supostamente, para a dureza imperativa da natureza humana. Pelo contrário, repousa em habilidades perceptivas que emergem, em cada ser, através de um processo de desenvolvimento num específico ambiente histórico (INGOLD, 2000, p. 25). A ecologia sensciente ou sensível seria, assim, pré-objetiva e pré-ética.

Por fim, o autor conclui que sua busca das origens e formação do conhecimento revela não uma ciência indígena alternativa preferencial a ocidental, mas algo como uma poética da moradia (poetics of $d$ welling), cujo sistema pode permitir a compreensão de processos ocidentais e não ocidentais o que parece apontar para a ideia de que existe a possibilidade de comensurabilidade entre as culturas.

Um contraponto desse entendimento pode ser encontrado nas discussões de Carneiro da Cunha (2009), para quem conhecimento tradicional é completamente distinto de conhecimento científico, são saberes incomensuráveis. Nesse sentido, destaca que a ciência moderna e hegemônica preocupa-se com generalizações dotadas de caráter de verdade, ou seja, com a produção de um único saber legítimo, enquanto as comunidades indígenas e tradicionais vislumbram uma gama de formas de compreender o mundo.

Consoante Carneiro da Cunha (2009), esse entendimento torna-se pertinente para a análise de como os conhecimentos nativos entram em diálogo com os conhecimentos científicos, em termos de garantias de direitos intelectuais. Assim, a autora tece uma reflexão acerca do fato de que, nos contextos de negociações sobre esses direitos, os povos tradicionais são levados a representar seus conhecimentos através de visões imaginárias sobre sua cultura, as quais consideram que seus conhecimentos são unificados como se formassem um bloco oposto ao conhecimento científico; frutos de uma invenção coletiva que circulam livremente pelas comunidades. Desse modo, as relações dos povos indígenas e seus conhecimentos são traduzidas politicamente nos termos de regimes de direito de propriedade coletiva ou domínio público.

A autora destaca que, na sociedade ocidental, predominam duas visões irredutíveis relacionadas à questão dos direitos intelectuais: uma noção de propriedade individual, cuja base está na concepção romântica de um autor criativo 
e que recai numa tirania do editor, e outra noção de direito coletivo e de domínio público, que recai na criação das licenças Creative Commons.

Ambas as noções não dão conta das relações entre pessoas, objetos e conhecimentos nas sociedades amazônicas. As mitologias dessas sociedades geralmente atribuem à origem de costumes, saberes e técnicas aos outros, ou seja, não tomam para si a criação que atribuímos a eles. Isto se articula a uma lógica de prestígio associado a bens exóticos, que está fundamentada no conceito de cultura como empréstimo, como bem demonstrou Lévi-Strauss em História de Lince e Viveiros de Castro com sua tese de incorporação do estrangeiro. Além disso, parece vigorar nessas sociedades um regime de 'rede de direitos heterogêneos' semelhante ao descrito para a melanésia, em que a cultura é passível de acumulação, empréstimos e transações, e que cada um possui direitos sobre determinados elementos de sua cultura, inclusive as crianças. Nesse regime, parece ser mais importante o direito a autorizar empréstimos e circulações culturais ou aquisições culturais do que o direito à exclusividade.

Viveiros de Castro (2002), através da noção de perspectivismo ameríndio, aponta para uma concepção diversa de conhecimento: enquanto para a ciência ocidental conhecer é objetivar, retirar a intencionalidade e a subjetividade, para o pensamento ameríndio conhecer é subjetivar, atribuir intencionalidade. "Eis aí uma lição que a antropologia poderia aproveitar" (VIVEIROS DE CASTRO, 2002, p. 361) .

Conforme Lasmar (2009), o conhecimento extrapola as formas orais em sua construção e transmissão, podendo inclusive obter maior ênfase nos modos não orais a depender da cultura que se observa e da fase do ciclo de vida em análise.

Todas essas teorias apontam para formas de saber e conhecer que não expressas necessariamente pela oralidade, mas que são construídas e reproduzidas

\footnotetext{
${ }^{6}$ No contexto das terras baixas das América do Sul, Albert (2002) realiza uma análise do discurso político de Davi Kopenawa, xamã Yanomami associado a ONGs indigenistas e ambientalistas com trajetória de luta pela demarcação das terras Yanomami invadidas pela corrida ao ouro, focalizando nos temas 'ecológicos' desse discurso. Interessante enfatizar que Albert demonstra que Davi Yanomami atribui violência predatória dos brancos à 'escuridão confusa' de seu pensamento 'plantado nas mercadorias', sublinhando um antagonismo irredutível entre dois modos de conhecimento, o dos estrangeiros, que tem raízes na escrita e o dos Yanomami, fundamentado na visão, no conhecimento xamânico (ALBERT, 2002, p. 10). A escrita, simulacro de visão, remete ao domínio dos manufaturados. O saber-ver xamânico é alcançado através da ingestão de alucinógeno ampliado pelos sonhos, e se opõe ao saber fazer predatório dos brancos, que toma a floresta como inerte.
} 
por pedagogias nativas e formas de produção do conhecimento que se respaldam na experiência e nos sentidos. Isso tudo nos remete aos modos de produzir e reproduzir conhecimento tipicamente infantis nos revelando que é preciso estar atento às formas distintas de produzir saberes, aos sujeitos que participam desses processos e os modos que eles encontram para reproduzir ou transmitir saberes.

Essas teorias nos orientam no sentido de atentar para as representações, ações e discursos das crianças a respeito de sua terra, sua vida junto à comunidade e suas representações sobre a importância dos territórios onde vivem para a produção de saberes e a vivência da infância nos moldes colocados pela etnia em que está inserida. Isto revela a importância de que todos os sujeitos sejam percebidos e considerados por esses processos de demarcação e por seus laudos.

\section{SOBRE OS LAUDOS E SEUS SUJEITOS}

Defender as crianças como sujeitos importantes a serem considerados nos processos de demarcação de terra consiste em questionar os laudos periciais antropológicos e seus sujeitos. Entendemos que os laudos antropológicos devem dar conta de um universo cultural presente em uma dada comunidade, considerando para isso a participação dos vários atores sociais que a constituem.

Curioso que esses laudos tenham se tornado cada vez mais históricos, ou mesmo elaborados a partir de termos jurídicos, abandonando o método etnográfico, antropológico por excelência. Devemos considerar que os grupos étnicos manifestam-se a partir da declaração de uma origem comum presumida e destinos compartilhados; logo, as categorias sociais de identidade étnica apresentam uma concomitância territorial, definida por referências compartilhadas de ordem física, simbólica e cosmológica (LEITE, 2005). Portanto a verificação dessas categorias étnicas deve se fundamentar na investigação etnográfica.

Se os laudos antropológicos se dedicam a identificar as concepções próprias às formas de autodefinição sociocultural do grupo, bem como a sua percepção de espaços, seus usos e valores, não vejo por que excluir dessas concepções as crianças, sujeitos constituintes dessas comunidades, com usufruto desses espaços e herdeiras de todo o legado. Sem perder de vista que as crianças não detêm os mesmos conhecimentos que os adultos, que elas informam outras coisas, que não são quantitativamente nem qualitativamente inferiores às coisas que os adultos informam. 
Sabemos que os laudos periciais antropológicos têm se dedicado à investigação minuciosa do passado, através da narrativa e da história oral, bem como de evidências de caráter documental. Entretanto as representações e as formas organizacionais que se deseja apreender têm expressão fundamental na realidade presente do grupo, devendo ser explicitadas na investigação etnográfica.

Se as narrativas de origem local e os relatos dos mais velhos são de grande valor, bem como as relações de parentesco evocadas através de uma genealogia de longo alcance, não percamos de vista que sua função é lançar luz sobre o presente do grupo que deve ser revelado através de um presente etnográfico que considere os sujeitos que experimentam essa realidade. Devem unir-se assim a temporalidade e a prática cultural, a segunda dizendo respeito também às crianças, afinal não se trata de utilizar o critério da ocupação da terra desde a chegada dos portugueses, mas o das formas tradicionais de ocupação por esses sujeitos. Com base nisso, entendo que deve ser a etnografia o fio analítico privilegiado desses estudos e não a memória.

Ora, se cabe ao grupo étnico identificar seu território e elaborar os critérios de pertencimento e exclusão espacial, assim como mapear suas fronteiras segundo suas próprias classificações e categorias, não vejo motivo para excluir desse processo atores tão ativos quanto as crianças, envolvidas no cotidiano do grupo, com utilização espacial distinta da dos adultos na aldeia. Muitos lugares são propícios às brincadeiras infantis, sendo frequentados pelas crianças apenas, razão pela qual dizemos que elas se apropriam dos espaços de maneira diferente dos adultos, mas também da terra e de suas fronteiras, das relações de parentesco e do ambiente a sua volta.

É isto que demonstra Miranda (2009) no interessante trabalho sobre as crianças Pataxó de Coroa Vermelha na Bahia, onde analisa o lugar das crianças na construção étnica do povo Pataxó, bem como a apropriação infantil do território através da participação das crianças no processo produtivo, especificamente na venda de artesanato. Segundo Miranda, nesse contexto de "intensa descontinuidade, flexibilidade e fluidez territorial, as crianças indígenas desempenham papel fundamental nos processos de territorialização e no fortalecimento da identidade étnica e da cidadania Pataxó, sobretudo, através da venda ambulante de artesanato" (MIRANDA, 2009). 
Não pretendo com isso transformar as crianças em sujeitos principais nesse processo, pois sei da importância da memória dos mais velhos, das narrativas, testemunhos e dos depoimentos conseguidos através da oralidade, mas entendo que, no exercício etnográfico de investigação dos usos e costumes da terra, da apropriação e construção de representações sobre aquele espaço praticado, nos termos de Certeau (1994), as crianças devam ser consideradas como sujeitos relativamente autônomos que são e com modos próprios de se apropriar e experienciar o mundo, especialmente no caso das crianças indígenas, cuja autonomia tem sido demonstrada em várias pesquisas (TASSINARI, 2001; 2007; TASSINARI; COHN, 2009), e por elas serem de grande valor para a manutenção e reprodução sociocultural de tais grupos étnicos.

Penso como Hirshfeld (2002) que as crianças são sujeitos privilegiados para a compreensão de suas culturas, por explicitarem aspectos que os adultos silenciam porque já estão familiarizados com eles ou já os "naturalizaram". Mas as crianças, ao contrário, reconhecem e expõem aquilo que os adultos não são mais capazes de enxergar.

Refletindo sobre as causas do desinteresse dos antropólogos com o universo infantil, Hirshfeld (2002) aponta alguns motivos teóricos e empíricos da marginalização das crianças em pesquisa etnográficas. O autor parte da premissa de que a antropologia as marginaliza por desconsiderar duas habilidades que elas realizam especialmente bem: crianças são boas em aprender cultura e são criadoras de suas próprias culturas. A relevância do foco da aprendizagem, com base exclusivamente no ensino, acaba por minimizar a importância do processo de aprendizagem cultural, fenômeno extremamente complexo, realizado com desenvoltura por elas. Além disso, as teorias de socialização superestimam o caráter socializador dos adultos, colocando exclusivamente neles o foco da agência esquecendo-se do caráter socializador das crianças e de sua própria contribuição em seu processo de desenvolvimento. Crianças não são boas apenas em aprender, mas também em ensinar.

Através de suas habilidades cognitivas, segundo Hirshfeld (2002), especializadas para esse fim e conquistadas justamente nessa fase da vida, elas ajudam a moldar também o mundo adulto, criando, sustentando e distribuindo formas culturais e vivendo também em suas próprias construções, fabricadas no convívio 
com outras crianças, que "circulam de criança para criança, além da influência dos adultos", corresponsáveis pela construção do modo de vida de uma sociedade (HIRSHFELD, 2002).

Vasconcelos (2011), analisando o parentesco e a circulação de crianças Guarani no litoral de Santa Catarina, demonstrou como as redes sociais e de parentesco através das quais circulam as crianças, embora parecessem forjadas pelos adultos, eram dinamizadas pelas crianças, que através de sua agência as transformavam, socializando a si mesmas e também aos adultos da comunidade, fazendo circular consigo mesmas palavras, significados e sentidos da organização social da aldeia.

Assim é que as crianças indígenas não apenas têm acesso a informações dos adultos pelo fato de compartilharem com eles o mesmo espaço e a mesma vida social, elas se apropriam dessas informações, significam ao seu modo e as fazem circular de maneira distinta, transformando-as quando estas seguem no sentido criança-criança, circulando dentro do próprio universo infantil, mas também no sentido crianças-adultos, cumprindo o seu caminho de volta. Por isso a agência infantil também é responsável por transformar a vida social e os modos como todos os membros da comunidade se apropriam desta.

\section{AS CRIANÇAS INDÍGENAS E O PROCESSO DE DEMARCAÇÃO DE TERRA}

As reflexões contidas neste artigo nasceram das minhas primeiras visitas feitas à Aldeia Bacurizinho, em Grajaú, no Maranhão, no ano de 2006, onde viria a desenvolver pesquisa sobre a infância experienciada pelas crianças indígenas daquela aldeia.

A presença de uma antropóloga em campo atraía para mim a companhia constante dos adultos interessados em tratar dos processos de demarcação de terra, fazendo queixas da demora do processo, dos conflitos de terra com os latifundiários e madeireiros locais, das ameaças constantes e da pressão a que estavam submetidos os indígenas.

Essa insistência em tratar dos processos de demarcação de terra com um antropólogo, constantemente associados que somos a essas questões e reconhecidos como importantes sujeitos nesses processos, angustiava-me por achar que isso distanciava de mim as crianças, e que boa parte do tempo que eu poderia 
aproveitar para observá-las e analisá-las, em suas brincadeiras e no cotidiano, eram despendidos ouvindo durante horas as queixas dos indígenas locais, especialmente os mais velhos e as lideranças da aldeia.

Qual foi a minha surpresa ao perceber, num término de uma dessas longas conversas, que as crianças que brincavam próximas a mim (inseridas que estavam num círculo de adultos), abaixadas rabiscando desenhos na terra, davam continuidade ao tema discutido pelos adultos e explicavam umas às outras, especialmente as maiores às menores, que eles estavam preocupados com a terra que era deles, mas era explorada pelos fazendeiros e que eles queriam sua terra de volta para poder "viver, caçar, trabalhar, brincar, passear, banhar no rio", etc..

Diante disso, atentei para a importância das representações das crianças para esses processos, dando vazão à conversa e buscando associar as práticas infantis e suas representações sobre a importância de ter as terras indígenas demarcadas.

A reviravolta de minhas reflexões sobre a infância, antes deslocadas de quaisquer preocupações em relação a esses processos que caracterizavam as aldeias em que eu estava inserida, refletia a falta de meu próprio reconhecimento de que as crianças também estão a par das chamadas "discussões sérias", os problemas que afetam a todas as pessoas que habitam essas terras, mas terminam sendo concebidas pelos pesquisadores como algo que diz respeito apenas aos adultos, como tudo o que é sério e diz respeito a questões políticas, econômicas e sociais em grande escala, tudo aquilo que as crianças "não têm competência" para discutir.

Apesar dos embates enfrentados pela antropologia da criança, preocupada em atribuir às crianças agência e poder de significação e transformação, e demonstrando que as crianças constroem opiniões próprias sobre todas as coisas que Ihes cercam e lhes afetam, nós tendemos a separar o universo adulto de um suposto universo infantil, em que as responsabilidades e os problemas sociais diriam respeito apenas ao primeiro campo semântico.

Essa minha reflexão me obriga a uma interessante digressão, assim acredito, para narrar um evento ocorrido em outra situação vivenciada por mim em campo, dessa vez entre as crianças remanescentes de quilombos do Maranhão. Em resposta ao Ofício/INCRA/SR.(12)G/No257/2006, elaboramos em equipe uma "Proposta para Elaboração de Relatórios Antropológicos de Identificação de Comunidades Remanescentes de Quilombo no Maranhão" antecedido por um survey de coleta de dados e reconhecimento de área. 
Certa manhã, no quilombo de Monges Belos em Itapecuru, perdida em minhas anotações de censo, parentesco e dados gerais da comunidade que compunham meu relatório de survey, Dé, um menino de seis anos de idade, se aproximou de mim perguntando o que eu fazia. Ocupada com meus papéis e anotações, no intuito de evitar qualquer interação com o menino que me ocupasse o tempo, respondi rapidamente que fazia uma "tarefa", na esperança de que ele entendesse que era uma tarefa da minha escola e me deixasse trabalhar em paz. Aborrecido com o meu descaso, Dé olhou-me com um muxoxo no canto da boca, um sorriso irônico de superioridade e disparou: "Eu sei! Tu tá estudando pra dizer que eu sou preto!". E, ato contínuo, se afastou balançando negativamente a cabeça como que repreendendo a minha ação de não dar ele a atenção que queria e, ao mesmo tempo, de precisar estudar para perceber algo que para ele era óbvio: ele é preto!

A atitude de Dé desmontou-me em minhas construções. Como eu poderia excluir do meu processo de construção de elaboração de relatórios de identificação dessas comunidades, as crianças? Desde essa experiência, inquietava-me a ausência das crianças nesses processos, e pus-me a refletir sobre essa ausência. O que ela nos revela?

A resposta as propostas feitas a esse edital não foram divulgadas, e nossa pesquisa nunca aconteceu. No entanto as reflexões que aquela situação em campo me colocou permaneceram comigo ao longo desse tempo e se fortaleceram com a minha chegada à Aldeia Bacurizinho (que luta para o reconhecimento da Terra Indígena Bacurizinho) e a situação que, de outra forma, se coloca mais uma vez: as crianças se interessam por esses processos e têm opiniões sobre eles.

Esse reconhecimento das crianças como sujeitos importantes a serem percebidos nos processos de demarcação de terra diz respeito ao reconhecimento de modo geral da agência das crianças, nas mais diversas esferas da vida social, estejam elas nos centros urbanos, nas aldeias ou no campo. A antropologia tem negligenciado o potencial das crianças como sujeitos privilegiados com um modo próprio de conceber o mundo, significá-lo, traduzi-lo e explicá-lo. Esse irreconhecimento colocou e coloca as crianças à margem de todos os processos que envolvem adultos e lideranças, que digam respeito às esferas política, social, religiosa; logo, marginaliza e exclui a criança como sujeito conhecedor de sua própria cosmologia e capaz de decodificá-la para nós, antropólogos. 
Essa negligência tem custado caro à antropologia e se estendido a outros campos. Que sujeitos são considerados nos laudos judiciais? Que sujeitos são investigados nas pesquisas de identificação de comunidades indígenas ou remanescente de quilombos? Que sujeitos são ouvidos sobre as relações de parentesco e com a terra? Ora, seriam as crianças desconhecedoras dessas relações? Não estariam elas vinculadas ao seu próprio espaço social, pelas relações de parentesco e a terra que habitam? Não estariam sujeitas aos mesmos riscos e ameaças que os adultos em geral? E os conhecimentos infantis não importam para o reconhecimento da importância da terra para esses sujeitos? O que difere crianças de adultos para que elas não sejam consideradas nesses processos se elas compartilham a territorialidade étnica do mesmo povo?

Além do mais, devo ressaltar que a minha posição de conceber as crianças como sujeitos importantes desse processo nasceu não apenas da constatação em campo da atenção que as crianças dedicavam a esses assuntos, bem como da importância que a terra e seus espaços exercem nos processos de construção do saber e do ser criança Tentehar-Guajajara, mas também em razão do fato de que os indígenas, de modo geral, têm grande consideração pelas suas crianças, e um respeito que as inclui em praticamente todas as esferas da cultura TenteharGuajajara, estas não sendo exclusas de coisa alguma. O ser criança indígena não equivale à experiência com a infância na cidade, em que espaços, horários e assuntos colocam à margem nossas crianças, sob a tentativa da segurança e da proteção que a nossa sociedade cunhou para garantia da vivência da infância (SOUSA, 2007).

Nas aldeias Tentehar-Guajajara, espaços e horários de adultos e crianças se encontram, e, em quase todas as esferas da vida cultural, há um espaço ou um papel a ser exercido por elas, sendo essas responsabilidades parte constituinte da formação do adulto Tentehar-Guajajara .

Os conhecimentos infantis repousam também na experiência das crianças no seio da comunidade, com as atividades desenvolvidas pelo seu povo no meio

\footnotetext{
${ }^{7}$ A esse despeito, digo que em uma das primeiras visitas feita a aldeia Bacurizinho, eu e meus alunos deparamo-nos com uma das casas da aldeia sendo cuidada por três crianças ao longo de toda a semana, pois a sua mãe, doente, fora à cidade para internação hospitalar levando a filha bebê e o marido, de modo que todas as atividades e a rotina da casa ficaram sob os cuidados de três crianças. Na cidade, um acontecimento desse tipo, seria polêmico, por não caber na nossa concepção de infância atrelada à segurança e proteção das crianças pelos adultos.
} 
em que vivem, os rituais vivenciados e as relações que se estabelecem entre pessoas e entre essas pessoas e a terra, (a morada da vida). Assim, conhecimento é experiência. Uma experiência adquirida através do contexto em que ocorre que é, em geral, abandonado pelos antropólogos, quando, no sentido de tornar a vida social inteligível, a antropologia deveria compreender o conhecimento em seu contexto social, afinal, a cultura é um processo inventivo contínuo. E, tal qual defende Wagner (2010) que só podemos apreender a cultura através da cultura, penso que o conhecimento só pode ser apreendido através do conhecimento. Do contrário através de que ferramentas acessaríamos o conhecimento, senão pelo conhecimento?

Isto nos remete a outra consideração: a necessidade de analisar o contexto emocional dos detalhes da conduta (BATESON, 1972), afinal, boa parte do conhecimento adquirido pelas crianças Tentehar-Guajajara não se dá pela via da oralidade ou da transmissão presente em nosso próprio sistema de aprendizagem, mas por processos sensoriais de descoberta do seu próprio ambiente, razão pela qual o lugar onde esse processo ocorre é tão importante e não pode ser descartado de toda tentativa antropológica de capturar os processos de construção do conhecimento de seu próprio mundo.

A vivência plena do lugar onde habita é condição sem a qual não se dá o processo de construção do saber, bem como a produção através do corpo da pessoa Tentehar-Guajajara. Desnecessário seria dizer que esse processo permeia toda a vida do ser Tentehar-Guajajara, mas é mais forte na infância quando se constroem as primeiras referências e elos entre a criança e o ambiente, relação que se perpetuará por toda a vida.

Essa experiência de construção do conhecimento e de relação com a terra, que permeia toda a aquisição do conhecimento, não pode ser entendida apenas pela linguagem, ainda que esta seja um importante recurso de elaboração e exposição do conhecimento. Embora haja uma ligação entre conhecimento e linguagem, o conhecimento não é apenas codificado em sistemas linguísticos, esta é uma lição a ser lembrada pelos antropólogos quando estes escrevem sobre conhecimento ou vida social, afinal, as regras de produção de relatos antropológicos podem limitar o que sabemos sobre outros tipos de experiência. Disso decorre a dificuldade do antropólogo com a racionalidade de outros modos de ser, além daqueles com os quais é culturalmente familiar. 
Como explicar um fenômeno cultural que não existe enquanto linguagem? As interpretações antropológicas serão válidas se implicam significados que os atores desconhecem? Como os antropólogos podem justificar o quadro interpretativo que eles usam?

As crianças indígenas Tentehar-Guajajara possuem maneiras próprias de se apropriar e representar a terra com um conhecimento específico sobre o parentesco, a terra e as pessoas. Esse conhecimento é incorporado, na medida em que as crianças se apropriam dele de maneiras diversas no cotidiano, através de experiências sensoriais, do contato com a terra, com os bichos e com a vegetação local. São, por isso, exímias conhecedoras de espécies animais e vegetais.

Essa in (corpo) ração é ainda mais forte quando essa série de elementos se reúne em manifestações rituais que garantem a construção do ser TenteharGuajajara, que tem início ainda na infância com o ritual de criança e se estende aos demais ciclos vitais através dos rituais da menina-moça, do rapaz, etc.

Esses rituais dependem de elementos ornamentais retirados de plantas (sementes) e animais (penas) locais, além da própria dieta ritual, seja para os que festejam, seja para a menina-moça reclusa em sua tocaia e com uma dieta específica baseada em ervas. A festa da criança marca o desmame, caracterizando o momento em que o bebê pode comer as primeiras caças adquiridas pelos homens da aldeia, aqui ela substitui a substância ou fluido materno pelos alimentos conquistados pelos homens da aldeia e oriundos da natureza.

Esse conhecimento da natureza não se reduz apenas aos gêneros alimentícios do cotidiano ou dos rituais, mas a um conhecimento geral de plantas, vegetações, sazonalidade, (época de rios, cheias, secas) espaços em que podem transitar e espaços em que não podem. Tudo isso torna as crianças TeheteharaGuajajara portadoras de uma consciência territorializada ${ }^{8}$.

Essa consciência territorializada é caracterizada não só pelo domínio das estações do ano, da época de determinados frutos, da utilidade de determinadas ervas e da utilização da carne e demais elementos dos animais. Ela está presente tanto em cantigas infantis, que remetem aos animais e plantas, quanto em espaços

\footnotetext{
${ }^{8}$ Suas brincadeiras são fundamentadas na territorialidade, naquilo que seu espaço físico/geográfico oferece. A prova disso é que elas estão embasadas nas estações do ano, nos rios na época da cheia se eles não são perenes, e na mata na época da seca.
} 
rituais: na tocaia, onde fica reclusa a menina-moça; ou no rio, onde são feitos os batismos cerimoniais da menina-moça ou onde é servido um banquete para a mãe d'água na festa da criança, etc..

Tal qual se dá com os rituais, as crianças são grandes conhecedoras das relações de parentesco. Não só detêm conhecimento dos graus de parentesco entre os adultos da comunidade, como reconhecem os seus parentes, os laços que os unem, e criam, através de sua agência, redes de parentescos fictícios com os seus pares: as demais crianças que são suas vizinhas, companheiras de grupos de brincadeiras ou de rituais coletivos, no interior de aldeia e em aldeias vizinhas Tentehar-Guajajara.

Esse domínio das relações de parentesco não está no cerne da construção dos laudos antropológicos? Ainda que as crianças não tenham a memória que se expande e estende às gerações antecedentes à deles próprios e de seus pais e avós, não podendo descrever através do tempo os seus ancestrais, o conhecimento da dinâmica das relações atuais exercem grande influência para o reconhecimento de uma comunidade indígena, pelo menos do que diz respeito aos laços de parentesco, sejam eles consanguíneos, afins, fictícios.

Se aqui não posso descrever detalhadamente a série de processos e eventos, evidências que fundamentam os meus argumentos, pretendo fazê-lo em breve numa etnografia da vivência da infância Tentehar-Guajajara, cujos dados etnográficos revelarão os processos de construção do conhecimento e das habilidades infantis a partir da experiência com o ambiente. E, se a produção da pessoa Tentehar-Guajajara passa inevitavelmente pela relação com o ambiente, e depende necessariamente dessa relação para construção de habilidades e percepções que conformam o ser Tentehar-Guajajara, e cuja ênfase ocorre especialmente na infância, por que razão não deveriam as crianças serem consideradas nos processos de demarcação de terra?

O meu argumento é de que as crianças são sujeitos relativamente autônomos, com elaborações próprias a despeito desses processos e representações a respeito da importância da terra e do ambiente em que vivem para serem o que são e o que virão-a-ser. Se o seu dispositivo principal para narrar essa experiência não é a linguagem, concatenada, articulada e coesa, como a utilizam os adultos, a antropologia deve, talvez, utilizar-se em seu métier dos mesmos mecanismos 
de que se utilizam as crianças para apreender aquilo que sua cultura julga importante e legítima: dos dados e expressões da sensibilidade, da imaginação e da intuição, daquilo que só pode ser captado sensorialmente e só pode ser entendido pela experiência narrada através da vivência contínua dos modos de ser criança Tentehar-Guajajara que repousa, acima de tudo, no ambiente que os cercam.

Se as crianças Tentehar-Guajajara são habilitadas (skillment) a ser e se tornar o que são, os antropólogos deveriam, talvez, habilitarem-se pelos mesmos processos quando em campo, como condição única para apreender aquilo que a oralidade, indígena ou acadêmica, não dá conta. Afinal, a antropologia precisa abandonar os diários de campo, as genealogias de parentesco, os censos e arquivos por um instante, e voltar-se à vida- aos sentidos e à imaginação dos modos de conhecer próprios de seus sujeitos- pelos caminhos da intuição.

\section{REFERÊNCIAS}

ALBERT, Bruce. O ouro canibal e a queda do céu: uma crítica xamânica da economia política da natureza. In: ALBERT, B.; Ramos, A. R. Pacificando o branco. Cosmologias do contato no Norte Amazônico. São Paulo: Editora da UNESP, 2002.

ALVARES, Myriam. Kitoko Maxakali: a criança indígena e os processos de formação, aprendizagem e escolarização. Revista Anthropológicas, Recife, n. 15, v. 1, p. 49-78, 2004. BARTH, Fredrik. O guru, o iniciador e outras variações antropológicas. Tomke Lask (Org.). Rio de Janeiro: Contracapa, 2000.

. Other knowledge and other ways of knowing. Journal of Anthropological Research, v. 51, n. 1, p. 65-8, 1995

. Cosmologies in the making. Cambridge: Cambridge University Press, 1987.

Ritual and Knowledge among the Baktaman of New Guinea. New Haven: Yale University Press, 1975.

BATESON, Gregory. Steps to an ecology of mind: collected essays in anthropology, psychiatry, evolution and epistemology. Londres: Jason Aronson Inc., 1972.

CARNEIRO DA CUNHA, Manuela. "Cultura" e cultura: conhecimentos tradicionais e direitos intelectuais. In: . Cultura com aspas e outros ensaios. São Paulo: Cosac Naify, 2009.

CERTEAU, Michel de. A invenção do cotidiano: artes de fazer. 11. ed. Petrópolis, RJ: Vozes, 1994. 
CODONHO, Camila. Entre brincadeiras e hostilidades: percepção, construção e vivência das regras de organização social entre as crianças indígenas Galibi-Marworno. Tellus, Campo Grande, MS, ano 9, n. 17, p. 137-61, jul./dez. 2009.

COHEN, Emma. Anthropology of knowledge. Journal of the Royal Anthropological Institute, v. 16, n. 1, p. 193-202, 2010.

COHN, Clarice. Antropologia da criança. Rio de Janeiro: Jorge Zahar, 2005. (Coleção Passo a Passo; 57).

A criança, o aprendizado e a socialização na antropologia. In: SILVA, A. L. da; NUNES, A.; MACEDO A. V. L. da S. Crianças indígenas: ensaios antropológicos. São Paulo: Global, 2002.

. A criança indígena: a concepção Xikrin de infância e aprendizado. 2000. Dissertação (Mestrado em Antropologia) - Universidade de São Paulo (USP), São Paulo, 2000.

GEERTZ, Clifford. O saber local: novos ensaios em antropologia interpretativa. Petrópolis, RJ: Vozes, 1997.

HIRSCHFELD, Lawrence. Why don't anthropologists like children? American Anthropologist, v. 104, n. 2, p. 611-27, 2002.

INGOLD, Tim. Culture, nature, environment: steps to an ecology of life. In: . The perception of the environment: essays on livelihood, dwelling and skill. London: Routledge, 2000. p. 13-26/420-421.

LASMAR, Cristiane. Conhecer para transformar: os índios do rio Uaupés (Alto Rio Negro) e a educação escolar. Tellus, Campo Grande, MS, ano 9, n. 16, p. 11-33, jan./jun. 2009.

LEITE, Ilka Boaventura (Org.). Laudos periciais antropológicos em debate. Florianópolis: NUER/ABA, 2005.

LOPES DA SILVA, A; NUNES, A.; MACEDO, A. V. L. S. Crianças indígenas: ensaios antropológicos. São Paulo: Global, 2002. (Coleção Antropologia e Educação).

MAUSS, Marcel. Sociologia e Antropologia. Tradução de Mauro W. B. de Almeida. São Paulo: Editora Pedagógica e Universitária; Editora da Universidade de São Paulo, 1969. v. 2.

MELLO, Flávia. Ciclo de Discussão sobre experiências e pesquisas a respeito da educação e infância indígena. Projeto Educação e Infância Indígenas, NEPI/UFSC. Florianópolis, 2006.

MIRANDA, Sarah. Aprendendo a ser Pataxó: um olhar etnográfico sobre as habilidades produtivas das crianças de Coroa Vermelha, Bahia. 2009. Dissertação (Mestrado em Antropologia Social) - Universidade Federal da Bahia (UFBA), Salvador, 2009.

RIBEIRO, Darcy. Diários índios: os Urubus-Kaapor. São Paulo: Companhia das Letras, 1996. 
SOUSA, Emilene Leite de. Infância e pobreza. In: CONGRESSO BRASILEIRO DE SOCIOLOGIA, 13. Anais... Recife: UFPE, 2007.

TASSINARI, Antonella Maria Imperatriz. Múltiplas infâncias: o que a criança indígena pode ensinar para quem já foi à escola ou A Sociedade contra a Escola. In: ENCONTRO DA ANPOCS, 33. Anais... Caxambu, 2009.

. Concepções indígenas de infância no Brasil. Tellus, Campo Grande, MS, ano 7, n. 13, p. 11-25, out. 2007.

Escola Indígena: novos horizontes teóricos, novas fronteiras de educação. In: SILVA, A. L.; FERREIRA, M. K. L. (Org.). Antropologia, história e educação: a questão indígena e a escola. 2. ed. São Paulo: Global, 2001.

TASSINARI, Antonella; COHN, Clarice. 'Opening to the other': schooling among the Karipuna and Mebengokré-Xikrin of Brazil. Anthropology \& Education Quarterly, v. 40, n. 2, p. 150-69, jun. 2009.

VASCONCELOS, Viviane C. C. Tramando redes: parentesco e circulação de crianças Guarani no litoral de Santa Catarina. 2011. Dissertação (Mestrado em Antropologia Social) Universidade Federal de Santa Catarina (UFSC), Florianópolis, 2011.

VIVEIROS DE CASTRO, Eduardo. Os pronomes cosmológicos e o perspectivismo ameríndio. Mana, Rio de Janeiro, v. 2, n. 2, p. 115-43, 2006.

Perspectivismo e multinaturalismo na américa indígena. In: A inconstância da alma selvagem. São Paulo: Cosac \& Naify, 2002.

WAGNER, Roy. A invenção da cultura. São Paulo: Cosac \& Naify, 2010.

\section{Sobre a autora:}

Emilene Leite Sousa: Pós-doutorado pelo Programa de Pós-Graduação em Antropologia da Universidade Federal da Paraíba (UFFPB). Doutora em Antropologia Social pelo PPGAS da Universidade Federal de Santa Catarina (UFSC). Mestre em Sociologia pela UFPB. Graduada em Ciências Sociais pela Universidade Federal de Campina Grande (UFCG). Professora Adjunta da Universidade Federal do Maranhão (UFMA). E-mail: emilenesousa@yahoo.com.br

Recebido em 11 de outubro de 2017

Aprovado para publicação em 21 de dezembro de 2017 